\title{
Improving outpatient warfarin use for hospitalized patients with atrial fibrillation
}

Daniel R. TOUCHETTE, Margaret E. MCGUINNESS, Steve STONER, David SHUTE, Jennifer M. EDWARDS, Kathy KETCHUM.

Received (first version): 19-Jul-2007 Accepted: 22-Nov-2007

\begin{abstract}
${ }^{*}$
Atrial fibrillation affects an estimated 5 million Americans and accounts for approximately $15 \%$ of all strokes. Few studies have successfully addressed patient screening, assessment, and introduction of appropriate antithrombotic therapy in patients with atrial fibrillation.

Objective: To assess whether an intervention improved planned antithrombotic prescribing at the time of discharge in hospitalized patients.

Methods: The study was a prospectively designed, retrospectively evaluated, non-blinded, historical control study of a pharmacist-initiated intervention. The intervention, consisting of pharmacist review and assessment of antithrombotic prescribing in patients with non-valvular atrial fibrillation, was conducted in an urban teaching hospital.

Results: Although antithrombotic prescribing was not significantly higher at discharge in the 252 enrolled subjects (control $67.3 \%$ vs. intervention $70.8 \% ; p=0.58$ ), a significantly greater number of patients had a written discharge plan for antithrombotic therapy (control $73.5 \%$ vs. intervention 88.3\%; $p<0.01$ ). The adjusted odds ratio that the study group was associated with an improvement in planned or actual warfarin use was 2.46 (95\% Cl 1.63-3.74). In addition, clinicians adhered to guidelines for antithrombotic therapy in patients with atrial fibrillation more frequently in the intervention group (control $70.4 \%$ vs. intervention $88.2 \% ; p<0.01)$.

Conclusion: A program designed to identify hospitalized patients with non-valvular atrial fibrillation, assess their need for stroke prophylaxis, and initiate appropriate antithrombotic therapy led to an increase in planned antithrombotic, and most importantly, warfarin use upon discharge from the
\end{abstract}

“Daniel R. TOUCHETTE. PharmD. MA. Assistant Professor of Pharmacy Practice. Department of Pharmacy Practice, College of Pharmacy, University of Illinois at Chicago, IL (USA).

Margaret E. MCGUINNESS. PharmD. Pharmacy

Manager. Northwest Cancer Specialists. Portland, OR (USA).

Steve STONER. Pharm.D. Regional Assistant Director, Clinical Pharmacy Services. Providence Portland Medical Center \& Providence St. Vincent Medical Center. Portland, OR (USA).

David SHUTE. MD. Medical Director. GreenField Health. Portland, OR (USA)

Jennifer M. EDWARDS. Pharm.D. Clinical Pharmacist. Pharmacy Department, Bozeman Deaconess Hospital, Bozeman, MT (USA).

Kathy KETCHUM. RPh, MPA. HA. Medicaid Program

Coordination. Drug Use Review and Management

Program, College of Pharmacy, Oregon State University. Corvallis, OR (USA). hospital. Confirmation that an increase in planned antithrombotic use upon discharge results in an actual increase in use after discharge is needed to determine the true effectiveness of this intervention.

Keywords: Pharmacists. Anticoagulants. Atrial Fibrillation. United States.

\section{MEJORA DEL USO AMBULATORIO DE WARFARINA EN PACIENETS HOSPITALIZADOS CON FIBRILACIÓN AURICULAR}

\section{RESUMEN}

La fibrilación auricular afecta aproximadamente a 5 millones de norteamericanos y aparece en el aproximadamente el $15 \%$ de todos los infartos. Pocos estudios han afrontado con éxito el cribado de pacientes, la evaluación y la introducción de tratamiento antitrombótico apropiado en pacientes con fibrilación auricular.

Objetivo: Evaluar si una intervención mejoraba la prescripción antitrombótica planeada en el alta en pacientes hospitalizados.

Métodos: El estudio fue diseñado prospectivamente y evaluado retrospectivamente, no ciego, con control histórico de una intervención iniciada por el farmacéutico. La intervención, que consistía en la revisión y evaluación por un farmacéutico de la prescripción antitrómbótica de pacientes con fibrilación auricular no valvular, se llevó a cabo en un hospital universitario urbano.

Resultados: Aunque la prescripción antitrombótica no fuie significativamente mayor en el alta en los 252 individuos (control $67.3 \%$ vs. intervención $70.8 \% ; \mathrm{p}=0.58$ ), un número significativamente mayor de pacientes tuvo un plan escrito al alta para el tratamiento antitrombótico (control $73.5 \%$ vs. intervención 88.3\%; p < 0.01). El odds ratio ajustado de que el grupo de estudio estaba asociado a un mejor uso de la warfarina planificada o real fue 2,46 (CI95\% 1.63-3.74). Además, los clínicos se adhirieron a las guías de tratamiento antitrombótico en pacientes con fibrilación auricular más frecuentemente en el grupo intervención (control $70.4 \%$ vs. intervención $88.2 \%$; $\mathrm{p}<0.01$ ).

Conclusión: Un programa diseñado para identificar pacientes hospitalizados con fibrilación auricular, evaluar su necesidad de prevención de infarto e iniciar tratamiento antitrombótico llevó a un aumento de antitrombóticos planificados, y más importante, al uso de warfarina al alta del hospital. Se necesita la confirmación de que un aumento en 
los antitrombóticos planificados lleve a un aumento en el uso real para determinar la verdadera efectividad de esta intervención.

Palabras clave: Farmacéuticos. Anticoagulantes. Fibrilación auricular. Estados Unidos.

\section{INTRODUCTION}

Atrial fibrillation affects over 5 million Americans. ${ }^{1}$ It has been estimated that the lifetime risk for the development of atrial fibrillation is approximately 1 in 4.2 The major complication of atrial fibrillation is stroke, with an estimated annual risk of $1.8 \%$ in untreated men and $3.5 \%$ in untreated women with atrial fibrillation in one study and may be as high as $8.5 \%$ in certain patient populations. ${ }^{3,4}$ Individuals with multiple risk factors or prior strokes are at greatest risk for stroke with rates exceeding $20 \%$ in some studies. ${ }^{5-8}$ Conversely, approximately $15 \%$ of all strokes are attributable to patients with atrial fibrillation. $^{8}$

Effective medications for patients with non-valvular atrial fibrillation are available. Warfarin has been shown to reduce the risk of stroke in patients with non-valvular atrial fibrillation by $62 \%{ }^{9}$ Aspirin confers a reduced protection, reducing stroke risk by $36 \%$. ${ }^{10}$ Also, patients with atrial fibrillation receiving warfarin live longer than those who do not. ${ }^{11,12}$ These agents are recommended for use in all eligible patients by the American Heart Association. ${ }^{7,13}$

Despite the demonstrated efficacy and effectiveness of warfarin and aspirin for stroke prophylaxis, a number of studies have demonstrated poor utilization rates in a variety of settings. ${ }^{14-19}$ Difficulties with antithrombotic prescribing have often been cited as reasons for the low utilization rates. ${ }^{20-22}$ Examples of patient-related barriers include advanced age, perceived low embolic risk, and perceived high risk for hemorrhage. Noncompliance and belief that a patient would refuse therapy have also been cited as reasons for not prescribing warfarin. ${ }^{23-25}$ Patient characteristics, clinical uncertainty, previous experiences with warfarin therapy, and the need for continued intense monitoring likely are major contributing factors to a physician's decision to use warfarin in a patient. Unfortunately, many of the cited barriers stem from a lack of clinical familiarity with the evidence supporting antithrombotic use and involve patients who would benefit most from stroke prophylaxis.

There are a number of studies addressing the monitoring and management of antithrombotic agents through anticoagulation clinics. ${ }^{26-35}$ In general, these studies have demonstrated an overall improvement in time within therapeutic range. Some studies have also demonstrated improved outcomes. ${ }^{28,34,35}$ Access to such clinics may improve antithrombotic use by removing some of the system barriers, but utilization still remains suboptimal. ${ }^{36,37}$ Unfortunately, there are very few studies that successfully address the screening, assessment, and introduction of patients to appropriate antithrombotic therapy. ${ }^{38-44}$ These studies were either conducted in a setting outside of the United States, ${ }^{38-42,44}$ failed to optimize warfarin use ${ }^{39-41}$ or were screening-only interventions. ${ }^{44}$

The study described in this paper addresses these major gaps in the literature. It describes a program designed to identify hospitalized patients with nonvalvular atrial fibrillation, assess the need for stroke prophylaxis, and initiate appropriate antithrombotic therapy prior to discharge. The objective of the study was to determine if this intervention was effective at improving the prescribing of, or having a discharge plan for, appropriate antithrombotic utilization at the time of patient discharge from hospital.

\section{METHODS}

This study was a single-site, inpatient, prospective, effectiveness analysis of a newly created pharmacy service at a suburban teaching hospital. It was nonblinded and utilized a prospectively identified historical control group. Study outcomes and other data were collected retrospectively, by chart review, to minimize the potential for interference by the study on the practice patterns being evaluated. Chart review was conducted by 2 non-investigator study nurses who were blinded to study group. This study was approved by the Oregon State University and Southwest Washington Medical Center IRB's and was conducted in accord with the ethical standards of the Helsinki Declaration of 1975.

Patients were identified for this study through EKG readings. At the end of each day, printouts for all patients with EKG readings consistent with atrial fibrillation were forwarded by the Cardiology Department to the Pharmacy. To be enrolled, patients had to be 18 years of age or over and have an attending physician from medicine, surgery, cardiology, or short term rehabilitation ( $<30$ days) services. Patients serviced by neurosurgery, trauma, short stay (emergency or observation units), psychiatric, cardiac surgery, gynecology, and oncology services were excluded. These exclusions were chosen as a quick way of separating patients with stays that were too short to identify and intervene on or instances where warfarin therapy may not be recommended, as in the case of surgical patients. Finally, when patients were admitted to the hospital more than once during the study period, only the first hospitalization was used in the analyses.

The control group was identified in the 3 month period prior to initiating the intervention throughout the hospital. Patients in the control group were identified as having an EKG consistent with atrial fibrillation. The list was generated by the Cardiology Department and forwarded to the Pharmacy Director and co-investigator (JE) who maintained the list of potential control patients. The study's inclusion and exclusion criteria were applied to the control group at the time of data collection. Clinical 
pharmacists were not assigned to these patients and there was no intervention other than routine medical care.

Prior to enrolling the intervention group, clinical pharmacists were recruited from the hospital staff to provide the intervention (in addition to their other regular clinical duties). Pharmacists were given a one-hour educational session by one of the study investigators (MM) focusing on appropriate identification of non-valvular atrial fibrillation and orientation to consensus guidelines on managing antithrombotic therapies in patients with nonvalvular atrial fibrillation. ${ }^{7}$ They were then provided several scenarios to assess their ability to apply the guidelines appropriately. Finally, instruction was provided on how to document their interventions in the patient chart.

As in the control group, patients in the intervention group were identified by an EKG consistent with atrial fibrillation. However, this list was then sent to the pharmacist assigned to follow the atrial fibrillation patients. This pharmacist determined if the patient was on warfarin from the medication administration record. If so, no further intervention was made. For patients not currently receiving warfarin, the patient chart was reviewed for confirmed or suspected non-valvular atrial fibrillation. Confirmation of non-valvular atrial fibrillation was obtained from the patient's physician, if necessary. A medication history was obtained in patients with confirmed or suspected non-valvular atrial fibrillation, focusing on current and prior antithrombotic use, risk factors for bleeding, and medications that interact with antithrombotic therapies through chart review and direct patient interview. A summary of the patient's therapy and a recommended plan was developed and communicated to the patient's physician. If a change in antithrombotic therapy was recommended, the pharmacist documented the recommendation in the Progress Notes section of the patient's chart. If a no response was received from the physician within 24 hours, the pharmacist contacted the physician to ensure that the recommendation was received and considered by the patient's physician. If a change in drug therapy was not necessary, but additional documentation was required, either the physician or pharmacist documented the additional information in the chart.

The purpose of this study was to determine the impact of the pharmacist intervention on the proportion of atrial fibrillation patients receiving antithrombotic therapies according to consensus guidelines. ${ }^{7}$ Our hypothesis was that the pharmacist intervention would increase appropriate antithrombotic therapy and the documentation of indications and bleeding risk factors, resulting in improved adherence to the guidelines. Patient demographics and other data including age, gender, type of atrial fibrillation, number and type of stroke risk factors, and number and type of bleeding risk factors to antithrombotic therapy were collected. Outcomes evaluated included warfarin utilization in hospital, aspirin utilization in hospital, and recommendations for warfarin and aspirin use in discharge plans.

The sample size was determined based on the expected difference between the intervention and the control group. Based on recently conducted cross-sectional analyses, we expect a warfarin utilization of approximately $50 \%$ in patients with non-valvular atrial fibrillation and without contraindications to its use. ${ }^{14-19}$ To detect a change in planned or actual warfarin utilization from $50 \%$ to $60 \%$ (10\% absolute or $20 \%$ relative increase) with a power of 0.8 and alpha of 0.05 using the Chi-square statistic would require 408 patients in each study arm. A change in planned or actual warfarin utilization from $50 \%$ to $70 \%$ (20\% absolute or $40 \%$ relative increase) would require 103 patients in each arm.

Data were analyzed using appropriate parametric and non-parametric tests for two independent samples to determine if there were significant differences between the two samples. Warfarin, aspirin, and overall antithrombotic actual or planned usage at discharge were compared between the two groups using chi-square tests. Adherence to consensus guidelines for antithrombotic therapy in atrial fibrillation was compared using chi-square tests.

A multivariate logistic regression model was developed to identify and control for confounding factors influencing the use or planned use of antithrombotic therapies. Independent variables considered for inclusion in the model were the intervention, patient age at admission, patient gender, number of stroke risk factors, and the number of bleeding risk factors. Candidate independent variables were required to have a $p$ value of less than 0.25 for inclusion in the multivariate model. All independent variables were entered into the multivariate model and all possible models were evaluated using the Score Statistic, except for intervention which was forced into the model. $^{45}$ The final model selected was chosen based on the simplest model that offers a considerable improvement over the next best model. Results were considered statistically significant if the $p$-value was $<0.05$. Statistical analysis was performed with SPSS Version 13.0 for Windows.

\section{RESULTS}

A total of 252 eligible patients were enrolled between May 1, 2001 and Feb 28, 2002. Ninetyeight patients were enrolled in the control group between May 1, 2001 and Jul 25, 2001, while 154 patients were enrolled in the intervention group between Sep 20, 2001 and Feb 28, 2002. There were no significant differences in demographics between the two groups at entry. Patients were closely matched in their type of atrial fibrillation. (Tables 1 and 2)

There were no significant differences between the control and intervention groups in the in-hospital use of warfarin at discharge $(41.8 \%$ vs. $45.5 \%$ respectively; $p=0.60$ ) or in the in-hospital use of 
aspirin at discharge $(33.7 \%$ vs. $35.1 \%$ respectively; $\mathrm{p}=0.89$ ). The proportion of patients receiving any antithrombotic therapy at discharge was also not significantly affected by the intervention (control $67.3 \%$ vs. intervention $70.8 \% ; p=0.58)$.

\begin{tabular}{|c|c|c|c|}
\hline & $\begin{array}{l}\text { Control } \\
\mathrm{n}=98\end{array}$ & $\begin{array}{c}\text { Intervention } \\
\mathrm{n}=154\end{array}$ & $P$ value \\
\hline Female & $57(58.2 \%)$ & $76(49.4 \%)$ & 0.20 \\
\hline Age at admission (SD) & $77.8(10.1)$ & $79.7(10.2)$ & 0.17 \\
\hline $\begin{array}{l}\text { Type of AF } \\
\text { New Onset } \\
\text { Chronic } \\
\text { Unspecified }\end{array}$ & $\begin{array}{l}10(10.2 \%) \\
49(50.0 \%) \\
39(39.8 \%)\end{array}$ & $\begin{array}{c}15(9.7 \%) \\
85(55.2 \%) \\
54(35.1 \%)\end{array}$ & 0.71 \\
\hline $\begin{array}{l}\text { Median (interquartile range) } \\
\text { Number of Stroke Risk Factors }\end{array}$ & $3(2-4)$ & $3(2-4)$ & 0.42 \\
\hline $\begin{array}{l}\text { Median (interquartile range) } \\
\text { Number of Contraindications }\end{array}$ & $0(0-1)$ & $0(0-1)$ & 0.57 \\
\hline
\end{tabular}

\begin{tabular}{|c|c|c|}
\hline Stroke Risk Factor and Level of Risk & Control & Intervention \\
\hline Previous TIA, stroke, or embolus (high) & $34(34.7 \%)$ & $50(32.4 \%)$ \\
\hline Poor left ventricular function (high) & $49(50.0 \%)$ & $89(57.8 \%)$ \\
\hline Diabetes mellitus (moderate ${ }^{a}$ ) & $30(30.6 \%)$ & $52(33.8 \%)$ \\
\hline Age over 75 years (high) & $68(69.4 \%)$ & $117(76.0 \%)$ \\
\hline Hypertension (high) & $56(57.1 \%)$ & $94(61.0 \%)$ \\
\hline Coronary artery disease (moderate ${ }^{b}$ ) & $43(43.9 \%)$ & $69(44.8 \%)$ \\
\hline Age 65 to 75 (moderate) & $18(18.4 \%)$ & $20(13.0 \%)$ \\
\hline Factors Increasing Bleeding Risk & Control & Intervention \\
\hline Active bleed (bleeding within last 24 hours or gross bleeding during current admission) & $9(9.2 \%)$ & $13(8.4 \%)$ \\
\hline Surgery within past 7 days & $11(11.2 \%)$ & $22(14.3 \%)$ \\
\hline Intracranial hemorrhage (hx or current) & $1(1.0 \%)$ & $4(2.6 \%)$ \\
\hline Uncontrolled seizures (hx or current) & $1(1.0 \%)$ & $2(1.3 \%)$ \\
\hline Current severe uncontrolled hypertension & $0(0.0 \%)$ & $2(1.3 \%)$ \\
\hline Documented poor compliance & $1(1.0 \%)$ & $4(2.6 \%)$ \\
\hline Recent bleed (active or gross bleeding $\leq 2$ months, incl. Heme + stools) & $5(5.1 \%)$ & $7(4.5 \%)$ \\
\hline Syncope ( $\geq 2$ falls within the past year, including syncope, seizures, blackouts ets) & $3(3.1 \%)$ & $7(4.5 \%)$ \\
\hline Dementia (includes senility, memory loss, forgetfulness, or memory deficit) & $14(14.3 \%)$ & $24(15.6 \%)$ \\
\hline $\begin{array}{l}\begin{array}{l}\text { Schizophrenia } \\
\text { schizophrenia) }\end{array} \\
\end{array}$ & $0(0.0 \%)$ & $1(0.6 \%)$ \\
\hline Diagnosis of current malignancy & $3(3.1 \%)$ & $6(3.9 \%)$ \\
\hline Thrombocytopenia (current) & $2(2.0 \%)$ & $1(0.6 \%)$ \\
\hline $\begin{array}{l}\text { Alcohol / illicit drug abuse (current documentation of alcoholism, evidence of ongoing } \\
\text { abuse or binge drinking) }\end{array}$ & $1(1.0 \%)$ & $4(2.6 \%)$ \\
\hline Other Factors Reducing Warfarin Use & Control & Intervention \\
\hline Terminal illness (patients undergoing supportive care only, end-stage illness) & $7(7.1 \%)$ & $4(2.6 \%)$ \\
\hline Patient refusal for therapy & $2(2.0 \%)$ & $6(3.9 \%)$ \\
\hline
\end{tabular}

There were significant differences between the control and intervention groups in discharge plans including warfarin $(56.1 \%$ vs. $77.9 \%$ respectively; $p<0.01)$, but not aspirin $(33.7 \%$ vs. $38.3 \%$ respectively; $p=0.50)$. There was a significant difference in the proportion of patients with a discharge plan for anticoagulation upon discharge (control $73.5 \%$ vs. intervention $88.3 \%$; $p<0.01$ ). Similar results were obtained when comparing the proportion of patients either on an antithrombotic agent in-hospital or with a discharge plan for one.(Table 3) A multivariate logistic regression analysis was conducted to adjust for potential confounding factors. Independent variables assessed in the model were study group (control vs. intervention), age at admission, sex, number of stroke risk factors, and number of bleeding risk factors. The final model included study group, age at admission, sex, and the number of stroke risk factors. All of these variables were statistically significantly associated $(p<0.05)$ with a plan for warfarin at discharge except for sex $(p=0.059)$, which was forced into the model. The odds ratio that the study group was associated with an improvement in planned or actual warfarin use was $2.46(95 \% \mathrm{Cl} 1.63-3.74)$.

Documented treatment matched the documented patient risk factors significantly more often in the intervention group than in the control group. Table 4 shows the proportion of patients on or with a discharge plan for antithrombotic therapy by their level of stroke risk and number of bleeding risk factors. Clinicians adhered to the Chest guidelines 
for antithrombotic therapy in patients with atrial fibrillation more frequently in the intervention group (control $70.4 \%$ vs. intervention $88.2 \% ; p<0.01$ ).

\begin{tabular}{|l|c|c|c|}
\hline Table 3 Proportion of patients receiving or with a written plan for antithrombotic therapy at discharge. \\
\hline & $\begin{array}{c}\text { Control } \\
\mathrm{n}=98\end{array}$ & $\begin{array}{c}\text { Intervention } \\
\mathrm{n}=154\end{array}$ & $\mathrm{P}$ value \\
\hline Receiving warfarin & $41(41.8 \%)$ & $70(45.5 \%)$ & 0.60 \\
\hline Receiving aspirin & $33(33.7 \%)$ & $54(35.1 \%)$ & 0.89 \\
\hline Receiving warfarin or aspirin (or both) & $66(67.3 \%)$ & $109(70.8 \%)$ & 0.58 \\
\hline Plan for warfarin & $55(56.1 \%)$ & $120(77.9 \%)$ & $<0.01$ \\
\hline Plan for aspirin & $33(33.7 \%)$ & $59(38.3 \%)$ & 0.50 \\
\hline Plan for warfarin or aspirin (or both) & $72(73.5 \%)$ & $136(88.3 \%)$ & $<0.01$ \\
\hline Receiving or plan for warfarin & $56(57.1 \%)$ & $121(78.6 \%)$ & $<0.01$ \\
\hline Receiving or plan for aspirin & $42(42.9 \%)$ & $66(42.9 \%)$ & 1.00 \\
\hline Receiving or plan for warfarin or aspirin (or both) & $80(81.6 \%)$ & $141(91.6 \%)$ & 0.03 \\
\hline
\end{tabular}

\begin{tabular}{|c|c|c|c|c|c|c|}
\hline \multirow[t]{2}{*}{ Level of stroke and bleeding risk } & \multicolumn{2}{|c|}{$\begin{array}{c}\text { No Antithrombotic } \\
\text { Therapy }\end{array}$} & \multicolumn{2}{|c|}{ Aspirin } & \multicolumn{2}{|c|}{ Warfarin } \\
\hline & \multicolumn{2}{|c|}{ Control / Intervention } & \multicolumn{2}{|c|}{ Control / Intervention } & \multicolumn{2}{|c|}{ Control / Intervention } \\
\hline Low stroke risk, no bleeding risk factors & $0.0 \%$ & $0.0 \%$ & $1.0 \%$ & $0.0 \%$ & $1.0 \%$ & $0.6 \%$ \\
\hline Medium risk, no bleeding risk factors & $1.0 \%$ & $0.6 \%$ & $0.0 \%$ & $0.0 \%$ & $0.0 \%$ & $1.3 \%$ \\
\hline High risk, no bleeding risk factors & $9.2 \%$ & $2.6 \%$ & $10.2 \%$ & $3.2 \%$ & $30.6 \%$ & $42.2 \%$ \\
\hline Low risk, at least 1 bleeding risk factor & $0.0 \%$ & $0.6 \%$ & $1.0 \%$ & $0.0 \%$ & $0.0 \%$ & $0.0 \%$ \\
\hline Medium risk, at least 1 bleeding risk factor & $0.0 \%$ & $0.0 \%$ & $0.0 \%$ & $0.0 \%$ & $1.0 \%$ & $0.0 \%$ \\
\hline High risk, at least 1 bleeding risk factor & $8.2 \%$ & $4.5 \%$ & $12.2 \%$ & $9.7 \%$ & $24.4 \%$ & $34.4 \%$ \\
\hline
\end{tabular}

\section{DISCUSSION}

This study demonstrated that an intervention in the inpatient setting could significantly improve the prescribing and/or documentation of a plan for antithrombotic therapy at the time of discharge in patients with atrial fibrillation. This was especially true for warfarin, with $21.5 \%$ more patients receiving or having a discharge plan for this agent. According to an economic model by Caro, increasing the appropriate use of warfarin by $50 \%$ (approximately our observed increase if all of the patients with discharge plans receive warfarin in the outpatient setting) would result in significant reductions in morbidity, mortality, and medical cost savings. ${ }^{46}$ Under the best-case scenario of assuming all patients with a discharge plan received warfarin in the outpatient setting (ie. there is a good system for transitioning from the inpatient to the outpatient setting), the Caro model predicts this intervention would prevent 1.6 strokes and cause 0.08 more bleeding events annually in a population of 350 patients (the estimated number of atrial fibrillation patients seen annually in this institution). The average annual medical cost savings of the program, not including the hospital program costs, extra drug, and monitoring costs, would be approximately USD 94,620.

To date, there have been few studies that have focused on programs to screen for patients with atrial fibrillation and fewer that affect antithrombotic prescribing. A nurse-led invitational screening program in the UK was effective at identifying some patients with atrial fibrillation, but the proportion of patients accepting the invitation varied by site (from $8 \%$ to $52 \%) .{ }^{44}$ There was no systematic attempt described in this study to treat patients once they were identified as having atrial fibrillation and antithrombotic utilization was not assessed. Similar screening initiatives have demonstrated that programs directed at higher risk patients are both effective and cost-effective for identifying patients with atrial fibrillation. $41,43,47$

Physician education and feedback programs have also been suggested as a method of identifying and treating patients with atrial fibrillation. Community programs taking this approach have demonstrated limited impact on outcomes. One such study of educational outreach visits provided information on stroke risk reduction practices to residential care staff and physicians in twenty facilities. ${ }^{39}$ At followup, there was no statistically significant difference in aspirin use for patients at risk of stroke. Another study provided general practitioners in one region with locally produced guidelines on stroke risk stratification and antithrombotic prescribing, followed by academic detailing visits. ${ }^{42}$ Compared with a similar region which did not receive the mailings and academic detailing, warfarin use was higher among hospitalized patients and in the general community. However, warfarin use remained low, with only $46 \%$ of hospitalized patients at a high-risk of stroke actually receiving warfarin.

An audit and provider feedback program for medical, pharmacy, and nursing staff resulted in improved antithrombotic therapy rates in the hospital setting. ${ }^{40}$ The appropriateness of the decision to use an antithrombotic agent increased from $72 \%$ immediately before to $92 \%$ four to eight weeks after the program. The effect was sustained, but attenuated, six months after the program. Warfarin utilization remained low, with only $40 \%$ of patients for whom warfarin was indicated actually receiving it after the intervention.

One study, employing similar methods and intervention to our study, was identified from the 
literature. $^{38}$ This study, performed in an elderly population, employed a pharmacist-coordinated multidisciplinary review process to assess patient risk and make recommendations on therapy. The intervention resulted in a significant increase in the proportion of patients receiving antithrombotic drugs by $21.5 \%$ (from $59.6 \%$ to $81.1 \%$ ). However, this increased antithrombotic usage was due to aspririn, with fewer patients receiving warfarin after the intervention than upon admission $(20.7 \%$ vs. $17.4 \%$ respectively).

Although both Bajorek et al and our study were successful in increasing appropriate antithrombotic prescribing, our results differ from theirs in some critical ways. ${ }^{38}$ It is unclear from their study why so few patients ended up received warfarin at the time of discharge, especially after consultation by the multidisciplinary team. One possible explanation is that their patient population was considerably older than our population (by 6 years on average). Cognitive impairment was cited as a contraindication to warfarin in roughly half of the patients. Another possible explanation was that the assessment perceived benefit to risk ratio for therapy with warfarin was more conservative in their study (or more aggressive in ours), with bleeding risk given more weight than in our setting. This may be due to regional beliefs as warfarin utilization appears to be much lower in all of the studies conducted in Australia. ${ }^{38-40,42}$ This is further evidenced by an increased warfarin utilization in our population, despite the presence of risk factors for bleeding. The time-dependent manner of many bleeding risk factors (e.g. bleeding with last 24 hours, surgery within past 7 days, etc.) may also explain why a large proportion of patients only had a discharge plan for warfarin. From the Australian studies and our model, it appears that an in-hospital model may be an effective method of increasing antithrombotic use, especially in the most vulnerable populations. The transition from a hospital discharge plan to actual warfarin use in the community (with appropriate follow up by an anticoagulation clinic) is crucial to the success of such programs. Furthermore, these programs need not be confined to patients with non-valvular atrial fibrillation. Patients with valvular heart disease may derive even greater benefit from appropriate warfarin use.

There are several important considerations regarding our intervention and the ability to test the effectiveness of the intervention. We were unable to follow patients after discharge. It was therefore not clear what proportion of patients with a written discharge order for an antithrombotic agent actually received that medication in the outpatient setting or how patients on warfarin were followed up and monitored. Potential barriers to patients receiving warfarin after a discharge note has been written include a lack of communication between the inpatient and outpatient primary care clinicians. Even if sufficient communication exists and the inpatient prescriber's intent is relayed to the outpatient primary care clinician, additional barriers may be present that prevent the patient from ever receiving appropriate antithrombotic therapy and monitoring. Outpatient practitioner biases, such as patient age, lower perceived embolic risk, higher perceived risk of hemorrhage, and previous experiences with warfarin can influence the decision to recommend warfarin after patient discharge. ${ }^{22}$ Lack of familiarity with current guidelines has also been cited as an important barrier. Since our inpatient intervention did not attempt to follow up with practitioners in the outpatient setting, there is the potential for decreased uptake once the patient is discharged from the hospital. Anticoagulation clinics may improve the uptake and monitoring of patients on warfarin in the community setting. ${ }^{48}$ Southwest Washington Medical Center does have an anticoagulation clinic to which many of the study patients may have been referred for ongoing monitoring and warfarin dose adjustment. ${ }^{26}$ The coordination of care between the hospital and ambulatory settings is an incredibly important aspect of patient care and safety. ${ }^{49}$

Another important consideration regarding whether or not to adopt this intervention strategy is the institution's ability to implement it. This study was originally designed to be conducted in four different health systems. Unfortunately we were able to implement the study in only one of the systems for various reasons. One of the health systems was not able to report patients identified with atrial fibrillation to the pharmacy department due to a software issue in the EKG equipment. One health system had a clinical pharmacist shortage and could not commit the necessary resources to staff the intervention. The final health system had a change in their pharmacy director at the time the study was to be implemented and was not in a position to support the study. These last two sites were prepared to conduct the intervention within a year of the study's implementation, but due to the delay, the study was already closed to enrollment.

There are several important methodologic limitations to this study that must be addressed. This study, although it does not meet all of the criteria for a pragmatic clinical trial, was designed to be a prospective, practice-based study involving clinically relevant alternatives and a diverse patient population. $^{50,51}$ The lack of randomization and concurrent control group can be seen as either a limitation or strength of this study. These study design limitations allow for the possibility that unseen confounders may impact the outcomes. However, we chose this design specifically, as it reduced the risk of the crossover bias that might occur with two concurrent research groups in a single institution. We believed that crossover bias would pose a more serious threat to this study's validity and therefore chose the current study design while attempting to control for observed differences between groups. Given the dramatic and sudden increase in warfarin use and planned use, it is unlikely that unseen confounders were responsible for the observed change in practice. However, it is possible that unseen confounding could bias the point estimates resulting in either an over- or under-estimation of the program's effectiveness. 


\section{CONCLUSIONS}

A program designed to identify hospitalized patients with non-valvular atrial fibrillation, assess their need for stroke prophylaxis, and initiate appropriate antithrombotic therapy led to an increase in planned antithrombotic use upon discharge from the hospital. Confirmation of this study's findings with a similar program using a prospective, randomized design is needed. Also, confirmation that an increase in planned antithrombotic use upon discharge results in an actual increase in use after discharge is needed to determine the true effectiveness of this intervention.

\section{CONFLICT OF INTEREST}

None declared. This study was supported by an unrestricted educational grant from DuPont Pharma.

\section{References}

1. Miyasaka Y, Barnes ME, Gersh BJ, Cha SS, Bailey KR, Abhayaratna WP, Seward JB, Tsang TS. Secular trends in incidence of atrial fibrillation in Olmsted County, Minnesota, 1980 to 2000, and implications on the projections for future prevalence. Circulation 2006;114(2):119-25.

2. Lloyd-Jones DM, Wang TJ, Leip EP, Larson MG, Levy D, Vasan RS, D'Agostino RB, Massaro JM, Beiser A, Wolf PA, Benjamin EJ.Lifetime risk for development of atrial fibrillation: the Framingham Heart Study. Circulation 2004;110(9):1042-6.

3. Fang MC, Singer DE, Chang Y, Hylek EM, Henault LE, Jensvold NG, Go AS. Gender differences in the risk of ischemic stroke and peripheral embolism in atrial fibrillation: the AnTicoagulation and Risk factors In Atrial fibrillation (ATRIA) study. Circulation 2005;112(12):1687-91.

4. Go AS. Efficacy of anticoagulation for stroke prevention and risk stratification in atrial fibrillation: translating trials into clinical practice. Am J Manag Care 2004;10(3 Suppl):S58-65.

5. Atwood JE, Albers GW. Anticoagulation and atrial fibrillation. Herz 1993;18(1):27-38.

6. Albers GW, Sherman DG, Gress DR, Paulseth JE, Petersen P. Stroke prevention in nonvalvular atrial fibrillation: a review of prospective randomized trials. Ann Neurol. 1991;30(4):511-8.

7. Albers GW, Dalen JE, Laupacis A, Manning WJ, Petersen P, Singer DE. Antithrombotic therapy in atrial fibrillation. Chest 2001;119(1 Suppl):194S-206S.

8. Wolf PA, Abbott RD, Kannel WB. Atrial fibrillation as an independent risk factor for stroke: the Framingham Study. Stroke 1991;22(8):983-8.

9. Hart RG, Benavente O, McBride R, Pearce LA. Antithrombotic therapy to prevent stroke in patients with atrial fibrillation: a meta-analysis. Ann Intern Med. 1999;131(7):492-501.

10. Atrial Fibrillation Investigators. Risk factors for stroke and efficacy of antithrombotic therapy in atrial fibrillation. Analysis of pooled data from five randomized controlled trials. Arch Intern Med. 1994;154(13):1449-57.

11. Currie CJ, Jones M, Goodfellow J, McEwan P, Morgan CL, Emmas C, Peters JR. Evaluation of survival and ischaemic and thromboembolic event rates in patients with non-valvar atrial fibrillation in the general population when treated and untreated with warfarin. Heart 2006;92(2):196-200.

12. Vemmos KN, Tsivgoulis G, Spengos K, Manios E, Toumanidis S, Zakopoulos N, Moulopoulos SD. Anticoagulation influences long-term outcome in patients with nonvalvular atrial fibrillation and severe ischemic stroke. Am J Geriatr Pharmacother. 2004;2(4):265-73.

13. Singer DE, Albers GW, Dalen JE, Go AS, Halperin JL, Manning WJ. Antithrombotic therapy in atrial fibrillation: the Seventh ACCP Conference on Antithrombotic and Thrombolytic Therapy. Chest 2004;126(3 Suppl):429S-56S

14. Tapson VF, Hyers TM, Waldo AL, Ballard DJ, Becker RC, Caprini JA, Khetan R, Wittkowsky AK, Colgan KJ, Shillington AC; NABOR (National Anticoagulation Benchmark and Outcomes Report) Steering Committee. Antithrombotic therapy practices in US hospitals in an era of practice guidelines. Arch Intern Med. 2005;165(13):1458-64.

15. Brass LM, Krumholz HM, Scinto JD, Mathur D, Radford M. Warfarin use following ischemic stroke among Medicare patients with atrial fibrillation. Arch Intern Med. 1998;158(19):2093-100.

16. Brass LM, Krumholz HM, Scinto JM, Radford M. Warfarin use among patients with atrial fibrillation. Stroke 1997;28(12):2382-9.

17. Gage BF, Boechler M, Doggette AL, Fortune G, Flaker GC, Rich MW, Radford MJ. Adverse outcomes and predictors of underuse of antithrombotic therapy in medicare beneficiaries with chronic atrial fibrillation. Stroke 2000;31(4):822-7.

18. Gurwitz JH, Monette J, Rochon PA, Eckler MA, Avorn J. Atrial fibrillation and stroke prevention with warfarin in the longterm care setting. Arch Intern Med. 1997;157(9):978-84.

19. Ruigomez A, Johansson S, Wallander MA, Rodriguez LA. Incidence of chronic atrial fibrillation in general practice and its treatment pattern. J Clin Epidemiol. 2002;55(4):358-63.

20. Bungard TJ, Ghali WA, McAlister FA, Buchan AM, Cave AJ, Hamilton PG, Mitchell LB, Shuaib A, Teo KK, Tsuyuki RT. Physicians' perceptions of the benefits and risks of warfarin for patients with nonvalvular atrial fibrillation. CMAJ 2001;165(3):301-2

21. Bungard TJ, Ghali WA, McAlister FA, Buchan AM, Cave AJ, Hamilton PG, Mitchell LB, Shuaib A, Teo KK, Tsuyuki RT. The relative importance of barriers to the prescription of warfarin for nonvalvular atrial fibrillation. Can J Cardiol. 2003;19(3):280-4.

22. Bungard TJ, Ghali WA, Teo KK, McAlister FA, Tsuyuki RT. Why do patients with atrial fibrillation not receive warfarin? Arch Intern Med. 2000;160(1):41-6.

23. Kutner M, Nixon G, Silverstone F. Physicians' attitudes toward oral anticoagulants and antiplatelet agents for stroke prevention in elderly patients with atrial fibrillation. Arch Intern Med. 1991;151(10):1950-3. 
24. McCrory DC, Matchar DB, Samsa G, Sanders LL, Pritchett EL. Physician attitudes about anticoagulation for nonvalvular atrial fibrillation in the elderly. Arch Intern Med. 1995;155(3):277-81.

25. Munschauer FE, Priore RL, Hens M, Castilone A. Thromboembolism prophylaxis in chronic atrial fibrillation. Practice patterns in community and tertiary-care hospitals. Stroke 1997;28(1):72-6.

26. Chamberlain MA, Sageser NA, Ruiz D. Comparison of anticoagulation clinic patient outcomes with outcomes from traditional care in a family medicine clinic. J Am Board Fam Pract. 2001;14(1):16-21.

27. Bussey HI, Rospond RM, Quandt CM, Clark GM. The safety and effectiveness of long-term warfarin therapy in an anticoagulation clinic. Pharmacotherapy 1989;9(4):214-9.

28. Chiquette E, Amato MG, Bussey HI. Comparison of an anticoagulation clinic with usual medical care: anticoagulation control, patient outcomes, and health care costs. Arch Intern Med. 1998;158(15):1641-7.

29. Conte RR, Kehoe WA, Nielson N, Lodhia H. Nine-year experience with a pharmacist-managed anticoagulation clinic. Am J Hosp Pharm. 1986;43(10):2460-4.

30. Ellis RF, Stephens MA, Sharp GB. Evaluation of a pharmacy-managed warfarin-monitoring service to coordinate inpatient and outpatient therapy. Am J Hosp Pharm. 1992;49(2):387-94.

31. Garabedian-Ruffalo SM, Gray DR, Sax MJ, Ruffalo RL. Retrospective evaluation of a pharmacist-managed warfarin anticoagulation clinic. Am J Hosp Pharm. 1985;42(2):304-8.

32. Lee YP, Schommer JC. Effect of a pharmacist-managed anticoagulation clinic on warfarin- related hospital readmissions. Am J Health Syst Pharm 1996;53(13):1580-3.

33. Wilt VM, Gums JG, Ahmed OI, Moore LM. Outcome analysis of a pharmacist-managed anticoagulation service. Pharmacotherapy 1995;15(6):732-9.

34. Locke C, Ravnan SL, Patel R, Uchizono JA. Reduction in warfarin adverse events requiring patient hospitalization after implementation of a pharmacist-managed anticoagulation service. Pharmacotherapy 2005;25(5):685-9.

35. Witt DM, Sadler MA, Shanahan RL, Mazzoli G, Tillman DJ. Effect of a centralized clinical pharmacy anticoagulation service on the outcomes of anticoagulation therapy. Chest 2005;127(5):1515-22.

36. Burkiewicz JS. Effect of access to anticoagulation management services on warfarin use in patients with atrial fibrillation. Pharmacotherapy 2005;25(8):1062-7.

37. Samsa GP, Matchar DB, Goldstein LB, Bonito AJ, Lux LJ, Witter DM, Bian J. Quality of anticoagulation management among patients with atrial fibrillation: results of a review of medical records from 2 communities. Arch Intern Med 2000;160(7):967-73.

38. Bajorek BV, Krass I, Ogle SJ, Duguid MJ, Shenfield GM. Optimizing the use of antithrombotic therapy for atrial fibrillation in older people: a pharmacist-led multidisciplinary intervention. J Am Geriatr Soc 2005;53(11):1912-20.

39. Crotty M, Whitehead C, Rowett D, Halbert J, Weller D, Finucane P, Esterman A. An outreach intervention to implement evidence based practice in residential care: a randomized controlled trial [ISRCTN67855475]. BMC Health Serv Res 2004;4(1):6.

40. Elliott RA, Woodward MC, Oborne CA. Antithrombotic prescribing in atrial fibrillation: application of a prescribing indicator and multidisciplinary feedback to improve prescribing. Age Ageing 2002;31(5):391-6.

41. Hobbs FD, Fitzmaurice DA, Mant J, Murray E, Jowett S, Bryan S, Raftery J, Davies M, Lip G. A randomised controlled trial and cost-effectiveness study of systematic screening (targeted and total population screening) versus routine practice for the detection of atrial fibrillation in people aged 65 and over. The SAFE study. Health Technol Assess 2005;9(40):iii-iv, ix-x, 1-74.

42. Jackson SL, Peterson GM, Vial JH. A community-based educational intervention to improve antithrombotic drug use in atrial fibrillation. Ann Pharmacother 2004;38(11):1794-9.

43. Maeda K, Shimbo T, Fukui T. Cost-effectiveness of a community-based screening programme for chronic atrial fibrillation in Japan. J Med Screen 2004;11(2):97-102.

44. Morgan S, Mant D. Randomised trial of two approaches to screening for atrial fibrillation in UK general practice. Br J Gen Pract 2002;52(478):373-4, 7-80.

45. Hosmer DW, Lemeshow S. Applied Logistic Regression. 2nd ed. New York: John Wiley \& Sons, Inc.; 2000.

46. Caro JJ. An economic model of stroke in atrial fibrillation: the cost of suboptimal oral anticoagulation. Am J Manag Care 2004;10(14 Suppl):S451-58; discussion S8-61.

47. Swancutt D, Hobbs R, Fitzmaurice D, Mant J, Murray E, Jowett S, Raftery J, Bryan S, Davies M, Lip G. A randomised controlled trial and cost effectiveness study of systematic screening (targeted and total population screening) versus routine practice for the detection of atrial fibrillation in the over 65s: (SAFE) [ISRCTN19633732]. BMC Cardiovasc Disord 2004;4:12.

48. Wittkowsky AK. Effective anticoagulation therapy: defining the gap between clinical studies and clinical practice. Am $\mathrm{J}$ Manag Care 2004;10(10 Suppl):S297-306; discussion S12-7.

49. Schnipper JL, Kirwin JL, Cotugno MC, Wahlstrom SA, Brown BA, Tarvin E, Kachalia A, Horng M, Roy CL, McKean SC, Bates DW. Role of pharmacist counseling in preventing adverse drug events after hospitalization. Arch Intern Med 2006;166(5):565-71.

50. Glasgow RE, Magid DJ, Beck A, Ritzwoller D, Estabrooks PA. Practical clinical trials for translating research to practice: design and measurement recommendations. Med Care 2005;43(6):551-7.

51. Tunis SR, Stryer DB, Clancy CM. Practical clinical trials: increasing the value of clinical research for decision making in clinical and health policy. JAMA 2003;290(12):1624-32. 